\title{
Overcoming Mathematical Helplessness and Developing Mathematical Resilience in Parents: An Illustrative Case Study
}

\author{
Janet Goodall ${ }^{1}$, Sue Johnston-Wilder ${ }^{2}$ \\ ${ }^{1}$ Department of Education, University of Bath, Bath, UK \\ ${ }^{2}$ Centre for Education Studies, University of Warwick, Coventry, UK \\ Email: j.s.goodall@bath.ac.uk, sue.johnston-wilder@warwick.ac.uk
}

Received 19 February 2015; accepted 2 April 2015; published 7 April 2015

Copyright (C) 2015 by authors and Scientific Research Publishing Inc.

This work is licensed under the Creative Commons Attribution International License (CC BY). http://creativecommons.org/licenses/by/4.0/

c) (i) 0pen Access

\begin{abstract}
A consideration of parental contribution to mathematical success in terms of affect is both timely and important. Many parents suffer from mathematics anxiety or helplessness in UK; there is a risk that this anxiety or helplessness be transmitted to their children. Here we illustrate the application of the construct "mathematical resilience" to developing positive parental engagement in mathematics. We used the method of a single case intervention study, in which the subject is a mother/daughter dyad and their relationship with mathematics. The object is made up of the concepts of learned helplessness and mathematical resilience. The intervention was 3 brief sessions between the second author and the mother. The mother kept a journal and after the intervention she was interviewed. As the dyad gained mathematical resilience, they were able to leave behind learned helplessness, resulting in a better relationship, raised self esteem and increased ability to engage with mathematical thinking.
\end{abstract}

\section{Keywords}

Mathematical Resilience, Learned Helplessness, Parental Engagement, Growth Zone

\section{Introduction}

The hidden help that many parents give their children with mathematics is well-known (e.g. Russell, 2002). However, the prevalence of mathematics anxiety and learned helplessness in children, and in the adults around them, presents a fundamental barrier to significant improvements in attainment outcomes (e.g. OECD, 2013). Addressing these core issues through the development of "mathematical resilience" (Johnston-Wilder \& Lee, 
2010) enables learners and the adults around them to overcome levels of learned helplessness, the extent of which seem to be unique to mathematics study, and equip them with the skills, attitudes and understanding necessary to become "progression ready" and gain qualifications, success and interest in further mathematical study.

This article focuses on how mathematics anxiety and helplessness might be remediated in the home. We present an illustrative case study of a mother-daughter dyad and a change in their relationship with mathematics arising from a brief intervention. We present this case as an individual, but illuminating, case study which tracks the mother, Heather, and her daughter, Rose, as they learn to feel helpless in relation to mathematics and then, through interaction with the Second Author, are able to acquire mathematical resilience, overcoming the learned behavior of helplessness. This is an example of what Masten (2003) calls "ordinary magic". As the UK is experiencing a culture of increasing pressure on parents to encourage their children to complete homework, the risk of negative experiences in relation to homework increases, especially when the parental role involves just supervision rather than more engaged forms of guidance (Patall, Cooper, \& Robinson, 2008). The notion of mathematical resilience can go some way to overcoming negative experiences and transforming them into productive, safe parent-child interactions that support learning of mathematics. We conclude the case study with suggestions for further research, as well as recommendations for schools in relation to working effectively with parents.

All names have been changed and all identifying markers removed in relation to the mother, daughter and school.

\section{Key Concepts}

In the paper, we examine the links between the concepts of learned helplessness and mathematical resilience. The first concept on which this paper is based is that of "learned helplessness" and the second, "mathematical resilience" (Johnston-Wilder \& Lee, 2010), which, we suggest, addresses learned helplessness in the case of mathematics. "Mathematical resilience" includes the construct of (self) agency.

\subsection{Learned Helplessness}

The term "learned helplessness" comes originally from research with animals, and describes "the interference with adaptive responding produced by inescapable shock and also as a shorthand to describe the process which we believe underlies the behavior" (Seligman, 1972: p. 408). The concept has been applied to humans and refined, for example in the work of Abramson, Seligman, \& Teasdale (1978).

"Learned helplessness" can be strongly related to the well-documented area of mathematical anxiety (for example, Hembree, 1990; Chinn \& Ashcroft, 2002). Miller holds that people experiencing learned helplessness behave as though they are unable to change unpleasant outcomes, even if they would, in fact, be able to avoid these (Miller, 1984). Overmier and Seligman propose that this situation arises when individuals learn—or perhaps it is better to say, become convinced - that there is no relation between events and outcomes (Overmier, 2002; Overmier \& Seligman, 1967; McCauley et al., 2008). Once this learning, however erroneous, has taken place, it informs the future actions and beliefs of the learner; it becomes an expectation of lack of ability to control or affect outcomes (Ball, 2007). What seems to be of importance in informing behavior and beliefs is not the actual relationship between action and consequence, but perception of or belief in such a connection (or lack thereof). Once a learner has come to believe that no action on their part will change the outcome of a process, they are much less likely to try to affect such outcomes in the future.

Abramson et al. (1978) discuss the concept of a global attribution of helplessness. This consists of an assumption on the part of the learner that helplessness will extend beyond the original situation to other, related situations. Not all helplessness is experienced as global; some may be specific, related to a particular event or time. In this case, the learner would not expect to be helpless in non-related situations. Further, these authors hold that helplessness may be external or internal. External helplessness relates to the situation per se-it cannot be solved (such as a riddle with no solution) or avoided (a tsunami or earthquake).Internal helplessness, however, relates not to the situation but to the agent-it is the learner herself who is unable to address the situation. In this case, the learner would expect others [such as the teacher] to be able to deal with the situation which has eluded them. Perceptions of internal helplessness can be correlated to lowered self-esteem (Abramson et al., 1978).

Regarding learned helplessness in relation to mathematics, the two people in our case study experienced specific internal helplessness. They were convinced that no further effort on their part would bring about success, 
but only in relation to the specific case of mathematics; their helplessness did not spill over into other areas of life. Further, the issue resided not in the subject of mathematics but in the agent attempting to overcome her difficulties; the helplessness is internal.

\section{2. (Self) Agency}

While it is not appropriate here to engage with the large field of philosophical and other thought around the concept of self agency, (Wiggins, 1991; Sewell, 1992; Emirbayer \& Mische, 1998; Bandura, 2000; Vincent, 2001; Guajardo \& Woodward, 2004; Biesta \& Tedder, 2006; Bayne, 2008; Edwards, 2009) it is necessary that we show what we mean by the term "agency". We are guided by the work of Emirbayer \& Mische (1998), who conceptualize human agency as “a temporally embedded process of social engagement”, informed by the past (in his habitual aspect), but also oriented toward the future (as a capacity to imagine alternative possibilities) (p. 963).

For the purposes of this paper, then, we see "agency" as a type of personal interaction, based on previous experience, in which a learner herself is able to address the situation in which they find themselves. When the members of the dyad in our case study act with agency, then, they act to good effect within mathematics on the foundation laid by previous experience outside mathematics.

\subsection{Resilience}

Resilience is a concept which is used as a partial explanation for student achievement which could be said to be "against the odds", meaning that it would seem unlikely that the student would achieve a good result.

Resilient students are, simply, those who achieve well, or at least better than might be expected, in spite of facing more or less severe disadvantage (Waxman, Gray et al., 2003). “Educational resilience”, as a construct, is based not on the idea of a student's ability, but is rather something which can be promoted by a focus on that which can be altered, that is, on factors which, if changed, can impact an individual's educational achievement for the better.

This is not the place for an in-depth examination of the concept of educational, or academic, resilience (Waxman, Gray et al., 2003; Schoon, 2006; Morrison \& Allen, 2007). We will concentrate on providing a clear definition (even though the terms are still used variously in the literature) which can then be related to the subset of mathematical resilience and to learned helplessness. This will provide the framework for the discussion of the case study.

Resilience enables students to deal with difficult situations, situations which might otherwise affect them adversely or be disabling, and allows them to find and use “adaptive outcomes” to such situations (Waxman, Gray et al., 2003: p. 2). This aspect of a student's personality is not static; it can be enhanced or reduced (if completely reduced, we would argue that the student had achieved a state of complete learned helplessness). Further, resilience includes agency on the part of the learner, agency which has been described as a "struggle” (Waxman, Gray et al. 2003: p. 2). As such, it is not an inherent aspect of personality, or need not be; resilience can be learned, enhanced and supported, so that pupils are better able to confront and overcome obstacles.

Benard (1991) lists four attributes generally exhibited by young people who are resilient: social competence, problem solving skills, autonomy and a sense of purpose. Johnston-Wilder \& Lee (2010), drawing on Dweck, add the importance of a growth mindset to this list. Again, it is possible to see a sharp contract between learned helplessness and resilience; those who have learned to be helpless, either globally or in relation to a specific stimulus or situation, may have problem solving skills but significantly do not choose or are not able to use them in these specific circumstances.

The inability to use existing skills in a specific situation relates clearly to the mother in our case study. She was capable of running a business as a self employed person, an enterprise which calls for autonomy, problem solving skills and a sense of purpose, and, as the business required her to be in contact with others, to gain and retain clients, it also required a certain level of social competence. Indeed THE MOTHER expressed this herself when she contrasted her ability to run her own business, including her accounts, with her lack of skills in and confidence around mathematics and supporting her daughter with mathematics.

MacDonald \& Validivieso (2001) (cited in Morrison \& Allen, 2007) and Masten (2003) suggest that a child’s environment can support the development of resilience, particularly in the areas of the classroom, their peer group and the family. For our dyad, the classroom and the school peer group were not experienced as sites for 
the development of (mathematical) resilience; on the contrary, both mother and daughter developed learned helplessness and also anxiety, that is, they gave up any concept of agency in relation to the learning of mathematics, in the home setting. Rather, it was through the mother's interaction with another adult (an alternative peer group setting), that the key to resilience was found, and once found, was reinforced through family interaction and support.

\subsection{Mathematical Resilience}

Johnston-Wilder \& Lee (2010) apply knowledge and understanding of what builds resilience explicitly to mathematics. Johnston-Wilder \& Lee $(2008,2010)$ have proposed the concept of a subset of educational resilience, which they have named "mathematical resilience". They hold that this is an important concept, as many students experience mathematics as a site of upset and (at least potential) failure.

Students with mathematical resilience possess a growth belief related to their abilities in this area. They do not perceive mathematics as exclusionary, as something that other people understand but that they do not; even when the student herself is experiencing difficulties, she retains her confidence in an eventual, successful outcome. The learner is aware of resources to assist her, and even if these are not to hand, she retains confidence in their existence and utility. The learner retains a positive affective stance in relation to mathematics. Significantly, the learner retains confidence in her ability to overcome mathematical obstacles, developing new skills if needed and drawing upon the help and support of others when needed. The development of mathematical resilience can be affected and supported with coaching (Johnston-Wilder, Lee et al., 2013).

The concept of mathematical resilience includes within it the belief that effort is both required and rewarded, that is, that the learner retains the agency to alter her situation. While educational resilience may be seen to be the antithesis of learned helplessness, mathematical resilience is that subset of resilience which allows students to overcome the particular form of anxiety that attaches itself to mathematics and the learning thereof. Ashcraft defines mathematics anxiety as "a feeling of tension, apprehension, or fear that interferes with math performance" (Ashcraft, 2002: p. 1).

Figure 1 is a visual representation of this concept, based on Chaiklin's (2003) concept of the zone of proximal development. Figure 1 suggests three "zones" or ways of experiencing learning from the point of view of the learner. In the green zone, zone one, the learner feels safe when dealing with problems on her own; she is able to use current knowledge to good effect and does not experience stress in relation to working in mathematics. Zone three, the red zone, is experienced as a polar opposite, as a place of great stress and lack of security and self belief. This area is dangerous to the learner, as she is unable to navigate it safely. Learners in this zone, which can differ from person to person, experience a "fight, flight or freeze" reaction, that is, a desire to battle against (rather than engaging with), or flee from the obstacle, or an inability to react cogently at all.

Between these two zones lies the "growth" zone, which is related to the "zone of proximal development". Remaining in zone one feels safe to the learner but, for many, this is unlikely to result in the acquisition of new knowledge or skills; moving directly to zone three, on the other hand, is also unlikely to result in new knowledge or skills, as the flight, fight or freeze reaction induced by this zone is not conducive to learning.

It is in the growth zone, zone two, that the learner will experience optimal growth (see also Zaretskii, 2009). The growth zone affords enough challenge to learn, a willingness to take managed risks and learn from mistakes, and goes hand in hand with the support of being part of a learning community that encourages the asking of

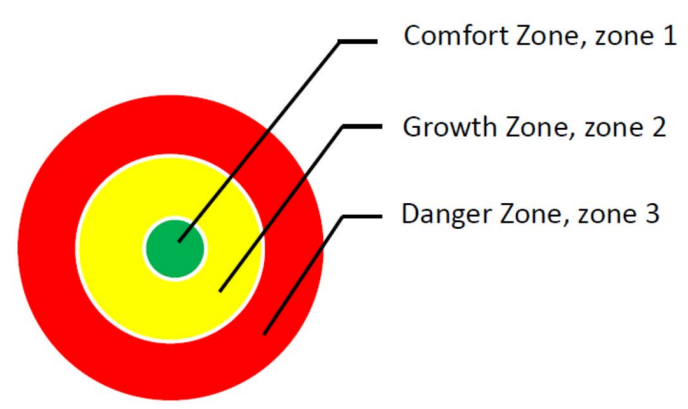

Figure 1. The growth zone diagram. 
questions and helps prevent the learner from disengaging or being unable to engage with the mathematics.

\section{Methodology}

"Case studies are analyses of persons, events, decisions... or other systems that are studied holistically by one or more methods. The case that is the subject of the inquiry will be an instance of a class of phenomena that provides and analytical frame-an object—-within which the study is conducted and which the case illuminates and explicates.” (Thomas, 2011: p. 513).

In this paper, we present an illustrative case study of a mother/daughter dyad; the dyad forms the case. One of the central ideas of case study methodology is that the research subject is a "reflexive social agent, situation within a multilayered social setting" (Wyness, 2010: p. 160). In this case, this dyad presented itself to the researchers during 2013. Informed consent was obtained from the mother of the dyad, and steps have been taken (such as the use of pseudonyms) to protect the identity of both members of the dyad.

Case studies investigate particular, individual instances, for their own sake, (Wyness, 2010), and of course what can be learned from them. This does not, however, mean that one is able to generalise from such instances; as such, what is presented here may be considered an "intrinsic" case study (Stake, 1967).

Our paper is focused on two people, and we consider this two-person grouping as a single case. Our emphasis here is not on the relationships between these two people, but rather on the interactions between members of this dyad and the concepts of learned helplessness and mathematical resilience, and with the intervention.

Thomas (2011) suggests that a case study must comprise within it two elements: a "practical historical unity", which is the subject of the study, and the framework through which this subject is studied or understood, which Thomas suggests is the object of the study. Using this understanding of case studies, the subject of ours is the mother/daughter dyad and their relationship with mathematics. The object is the lens made up of the concepts of learned helplessness and mathematical resilience.

As well as describing the interactions of the mother-daughter dyad with learned helplessness and, later, mathematical resilience, we seek to explain and understand these interactions as internal to the subjects.

The object of our case study, then, is a conceptual framework, as illustrated in Figure 2. Central to the framework is the concept of learned helplessness, as discussed above. This is bounded on each side; on the left by the negative experiences of the dyad, and on the right by the maths anxiety that results from those experiences. Learned helplessness was the original and long standing response to that anxiety. Below all of these is the ultimate outcome of the interactions between the dyad and Author 2, namely mathematical resilience.

Author 1 had not previously met Heather and joined the project as an objective, independent evaluator with broad and deep experience of researching parents. Author1 interviewed Heather after the intervention; the interview lasted over an hour. The main points of the narrative are recounted here, although any identifying details have been removed.

\section{The Case-Heather and Rose's Story}

Heather is in her late 20s; Rose was, at the time of the interview, in her final year of primary school. Heather

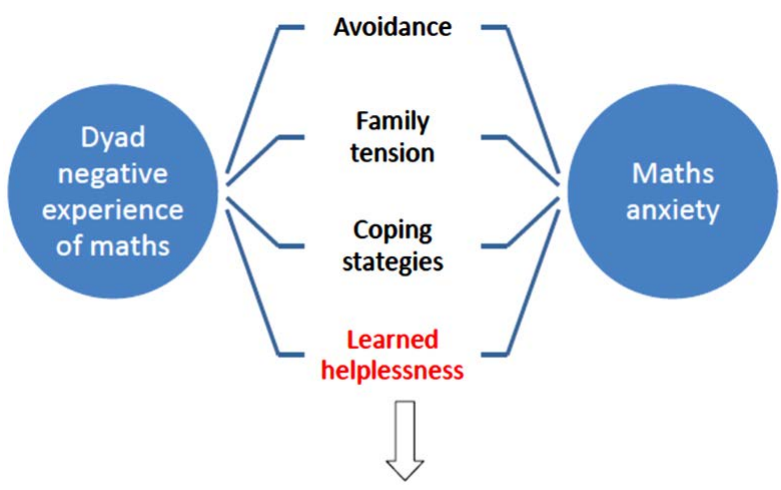

Mathematical Resilience

Figure 2. The conceptual framework. 
reported that she first encountered difficulties in mathematics when she, too, was in the final year of primary school; she was reprimanded by her teacher for using the wrong method to arrive at an answer, and the teacher "made me feel stupid in front of my peers when I explained my methods". Up to that point, Heather had enjoyed the complexity of the work, and finding her own ways to solve problems. However, this incident was a turning point for her, as "I pretty much began to give up interest when I couldn't understand the methods I was expected to stick so strictly to". Throughout the rest of her schooling, which ended without any qualifications, mathematics remained problematic for Heather. However, she was able to find coping strategies and became self employed, saying that "a calculator was my best friend".

When Rose began school, Heather was and remained an engaged parent, attending parents' evenings regularly, conversing with teachers, and supporting Rose in her work. However, it soon became apparent that Rose was falling behind in mathematics. In spite of the difficulties such a path presented for her, Heather "would swallow more and more pride and ask [the teachers] how I can help and explained what a negative experience it was at home with Rose", as working on mathematics would lead to "falling out, shouting, tears, avoidance, feeling stupid on both parts, Rose putting herself down, me trying to restore her confidence but both of us too tense and stressed for it to make any difference". Heather was asking teachers how she could help her daughter, but she was consistently told that she could not, "even if you did have a GCSE then you wouldn't be able to help much because it wouldn't make much sense to Rose and it would probably just confuse her as all the methods have changed now". Heather was left feeling helpless to support her daughter.

Heather recounted a belief that her concerns that Rose was falling behind in mathematics were not taken seriously in the first years of primary school, "I've been told not to worry, she'll catch up, it will be fine”. This, in spite of the fact that Heather had explained how negative her experience with mathematics had been and how hard working with Rose on mathematics problems was becoming. Eventually, Heather acquiesced and declared "it was probably best left to the school and as we didn't really have a clue about their methods we were stabbing in the dark”. By year 6, Heather reported, Rose was at a much lower level in mathematics than most of her peers and, when asked, "the teacher asserted that it would not be possible for Rose to attain the appropriate level by the end of primary school." "I clearly remember feeling like I'd just took a blow to the stomach, complete shock, followed later by guilt for not doing more, anger for being let down so much myself as a child and now my daughter too and working constantly to not let that cause a domino effect with Rose but yet here I was..."

The situation for Rose did not improve, "She came home upset and frustrated that [her teacher] had crossly said she wasn't trying hard enough, the tears were pricking her eyes and the face that spoke a thousand words told me she had tried but just couldn't make the link”. Here it seemed to Heather that her experience in school mathematics was being repeated for her daughter, in spite of all the mother's attempts to prevent it. The support promised by teachers did not materialise, and Heather reported that "when the school have been so discouraging [saying] that I could not help even I was any good at the subject, you kind of lose hope and faith in yourself”.

Heather avoided all discussion of mathematics whenever possible, using diversion tactics if Rose asked questions other than those related to homework; Heather refers to this as "classic avoidance skills and I think I'd become quite a master at it, in the end I did it so naturally that at times I did want to engage in the conversation but had already avoided it...”. The avoidance spilled over to Rose, as well, “...if she told me she had maths homework on a Friday we probably wouldn't approach it till Sunday but it would play on my mind and I'd spend my whole weekend tense, bracing myself for the onslaught of the dreaded maths homework". This was not an easy stance for Heather to take: “I couldn’t accept where I was mathematically and was ashamed as well as feeling guilty because I knew in my heart I could and should have been doing more to help her". There was also a disconnect between rhetoric and reality, "I always tell her... 'do your best, chuff the rest and carry on regardless' and yet why should she believe her best was good enough when I could not accept my best as good enough?”

The situation came to a head when Rose presented her mother with a practice SAT mathematics paper. Working on the paper caused disruption between Rose and Heather, "well to say I damaged her confidence more and we fell out again big time was an understatement, it was like a big spot had finally come to a head and was ready to explode".

Heather took the paper to Author 2, with whom she had prior contact. Knowing that Author 2 worked in the field of education, Heather hoped that Author 2 could help them, "other than more shame and embarrassment what did I have to lose?” But Heather dreaded the discussion, "I mentally prepared myself for the looks or response I might get... I thought she would think I was stupid, she could laugh at me and wonder how I've managed to be self employed with such short comings, I thought she would be shocked at my shortcomings... but hoped that she would help Rose with some private lessons". 
Author 2's reaction, however, was far from what Heather was dreading, "I was stunned at the response... she was so calm and understanding it was as if I was asking for directions somewhere, she was just not fazed by my issues with maths at all” .... I couldn’t believe it, ... I actually thought, "isn't this the part where I feel really stupid and frustrated as it is a year 6 paper but I don’t think it mattered if it was a degree paper or reception class, there was just this just feeling of acceptance and no expectation to be anywhere above where I was.”

Author 2 promised to help Heather to support Rose, "I didn't believe this possible really, I'd already written myself off as it being too late for me, but I trusted Author 2 and decided to give it my best shot”. Rose met Author 2 and "it was quite clear Rose hated maths and thought that she was just no good at it, pretty much a reflection of myself really..." After two meetings with Author 2, the mother and daughter "left with a better understanding that average aside we were exactly where we were supposed to be and a new sense of pride and respect for ourselves and each other”. Author 2 gave Heather a mathematics dictionary, which Rose subsequently took to school. Her teacher asked to borrow it, "this filled Rose with so much confidence, it was brill.... this experience also encouraged Rose with mathematics and helped overcome the lack of confidence she had and actually gave her an empowered feeling...”. The relationship between mother and daughter has benefitted, "now when she asks me a question and I don't know we both find a way to figure it out, before she used to give up at that part...”.

From there, the story takes a much more encouraging turn, "Author 2 helped me overcome my anxiety and through that as well as meeting Rose a couple of times we helped her overcome hers, me and Rose are now learning together with lots of tips from Author 2 on how to incorporate mathematics into daily life and accepting where we are... the only major change is confidence and we're both so much happier and actually enjoy the subject... Author 2 made me realize that I'm not the teacher, I'm the mum and that it's ok".

Rose has received a good teacher assessment of her mathematics, "she can now go up to senior school much better equipped for learning and a lot keener and happier in mathematics, I'm so proud it feels like a real achievement considering her class teacher didn’t believe she could do it...”.

\section{Discussion}

People can give up trying because they lack a sense of efficacy in achieving the required behavior, or they may be assured of their capabilities but give up trying because they expect their behavior to have no effect on an unresponsive environment or to be consistently punished (Bandura, 1977: p. 204).

In this, Bandura uses the notion of efficacy, focusing on personal beliefs about whether an actor has agency in a given situation. Johnston-Wilder \& Lee (2008), in coming to their concept of mathematical resilience, have discussed what they term "mathematical abuse"; by this, they mean events which "result in damage to the way pupils think about mathematics and to their ability to succeed in learning mathematics” (p. 56). If we accept the term "abuse" in relation to the outcome (if not the intention), then it is clear that both mother and daughter have suffered this in relation to their ability to "do" mathematics; their agency, their self efficacy and belief in their ability to grow the skills necessary to solve problems, had been severely undermined. That they had not been completely destroyed is demonstrated by the mother's final effort to seek help from Author 2. The extent of the damage, however, is shown by the way that search was framed, as "too late for me" and the terms which were used to describe the approach to Author 2 and the trepidation within which it took place.

Both mother and daughter had become "maths anxious". In relation to the concept of "learned helplessness", what is learned is that outcomes are uncontrollable (Abramson \& Sackheim, 1977; Abramson, Seligman et al. 1978), which Heather reports from her early experiences, "I pretty much began to give up interest” when her alternative means of arriving at an answer is ridiculed in a mathematics lesson. This is reinforced in relation to support for her daughter; Heather is told she could not help even if she had a mathematics GCSE, and by another teacher that she would "probably confuse" Rose if she tried to help. Her daughter was also drawn into this cycle of non-learning, when she was told by a teacher that her lack of achievement in mathematics was a result of lack of effort. Eventually, Rose came to believe that problems were beyond her reach to solve.

As Abramson et al have pointed out, however, "when a person finds that he is helpless, he asks why he is helpless” (1978: p. 50; emphasis in the original). We argue here that mathematics resilience goes some way-a very great deal of the way-to answering this question for Heather, and for Rose.

Using Abramson's schema, we can see that what Heather and Rose experienced may be called "personal” rather than universal helplessness. A feeling of universal helplessness arises when the subject is convinced that no one can solve the issue at hand. This clearly was not the case, as part of the "shame", "embarrassment" and "guilt" reported by Heather results from the fact that others are obviously capable of solving the problems set in 
the mathematics lessons. Indeed, it is this knowledge that allows Heather to seek help from Author 2 in the first place; had the helplessness been universal in character, there would have been no point in seeking help.

Feelings of failure result from an inability to attain an internal goal; one does not, for example, generally speak of failure in situations such as being caught in a flash flood (Abramson et al., 1978). Again, when Heather speaks of her relationship with mathematics, although she does not use the word failure, the sense is there, as she speaks of guilt, shame, etc.

Rotenberg sees the essence of learned helplessness as "an outcome of numerous failures in attempts to achieve important goals and desires" that results in "a renunciation of search” (Rotenberg, 2012: p. 1), by which is meant a cessation of the search for a solution. We see this in Heather, who gives up asking teachers for supportive homework for Rose, and in her own coping strategies, "my calculator was my best friend". It is also manifested in what Heather calls "classic avoidance skills", in which she would direct discussions away from mathematics; it is also there when she puts off the advent of mathematics homework, "if she [Rose] told me she had maths homework on a Friday we probably wouldn't approach it till Sunday”, even though she would spend the intervening time "tense, bracing myself for the onslaught of the dreaded maths homework". Rotenberg holds that the use of activity prevents helplessness. In Heather's case, as we have seen, such activity was consistently argued against by the professionals-the teachers-with whom she interacted, and importantly, on whom she relied as experts.

Helplessness need not be pervasive; it can be fairly tightly located within the individual's outlook. This was the case for Heather, who found coping mechanisms for her issues with mathematics, "my calculator was my best friend", and was able to run a small business. It is interesting to note, however, that Heather does speculate that Author 2 might not understand how Heather could run a business, without having mastered mathematics. Others have found that individuals are more than able to function well in some areas of life, while presenting an attitude of helplessness in others (Singer, 2012). This again would argue that Heather experienced not global, but specific helplessness; she was able to create and maintain a career, and face many other challenges in life.

Note that Author 2 did not teach more mathematics. She separated out the role of "parenting for mathematical resilience" from any responsibility for knowing any school mathematics. She listened, was calm and understanding, accepting. She enabled Heather to feel safe. She encouraged inclusion by raising Heather's awareness of using mathematical thinking (not "school maths") in her everyday life. She spoke about and modeled a growth mindset. She conceived of Heather as "mum" not "teacher", shared with her the growth diagram (see Figure 1) and focused on the role of safeguarding, asking questions, remaining calm and helping the child to become agentic.

The framework used for analysis in this case study not only offers valuable insights into the experiences of the dyad in question, but goes some way toward providing a remedy for the negativity and failure they had previously experienced. A strategy that is focused on the development of mathematical resilience in parents and carers and their children may thus offer hope of progress. This means a focus on each of the elements that together make up the concept of mathematical resilience: growth mindset, inclusivity, self agency and resources.

We conclude the case study with suggestions for further research, as well as recommendations for schools in relation to supporting parents.

\section{Recommendations}

In this case study, we have presented illustrative evidence of the negative experiences that sometimes ensue when parents feel under pressure to support mathematics whilst being mathematically anxious themselves. We have given an account of how this can be addressed successfully and how it might be considered to be possible that all parents, whether mathematics anxious or not, may be capable of promoting, mathematical resilience and supporting mathematics learning more effectively.

The focus of the work with Heather was on what parents can do (focus on safety, model curious behavior, encourage the child to seek support from peers, resources) and not what they can't do, or what teachers feel that they should not do (bearing in mind the comments teachers made about Heather being "unable" to help Rose with her homework).

Parental engagement with children's learning is a powerful lever for children's achievement (Desforges \& Abouchaar, 2003; Jeynes, 2005; Goodall \& Vorhaus, 2011; Jeynes, 2012), but only when parents feel enabled and empowered to engage, and only when they and schools have a clear understanding of what effective engagement entails (Goodall \& Vorhaus, 2011). We recommend that schools recognize the possibility of trans- 
formative effects of mathematical resilience for parents as well as children, and seek to support development of this resilience within their local communities.

We also recommend that the growth model in Figure 1 and the importance of mathematical resilience be shared with parents-this could be as part of a support program for parenting for mathematical resilience which aims to enable parents successfully to manage their own anxiety while supporting their child's development; based on Heather's experience this might be as short as 3 sessions, and easily incorporated into schools' other work with parents.

\section{References}

Abramson, L. Y., \& Sackheim, H. A. (1977). A Paradox in Depression: Uncontrollability and Self-Blame. Psychological Bulletin, 84, 838-851. http://dx.doi.org/10.1037/0033-2909.84.5.838

Abramson, L. Y., Seligman, M. E., \& Teasdale, J. D. (1978) Learned Helplessness in Humans: Critique and Reformulation. Journal of abnormal psychology, 87, 49. http://dx.doi.org/10.1037//0021-843X.87.1.49

Bandura, A. (1977). Self-Efficacy: Toward a Unifying Theory of Behavioral Change. Psychological Review, 84, 191. http://dx.doi.org/10.1037/0033-295X.84.2.191

Bandura, A. (2000). Exercise of Human Agency through Collective Efficacy. Current Directions in Psychological Science, 9, 75-78. http://dx.doi.org/10.1111/1467-8721.00064

Bayne, T. (2008). The Phenomenology of Agency. Philosophy Compass, 3, 182-202. http://dx.doi.org/10.1111/j.1747-9991.2007.00122.x

Benard, B. (1991). Fostering Resiliency in Kids: Protective Factors in the Family, School, and Community. Portland, OR: Northwest Regional Educational Laboratory.

Biesta, G., \& Tedder, M. (2006). How Is Agency Possible? Towards an Ecological Understanding of Agency-as-Achievement. Learning Lives: Learning, Identity, and Agency in the Life Course. Working Paper Five, Exeter: Teaching and Learning Research Programme.

Chinn, S., \& Ashcroft, J. (2002). The Use of Patterns. In T. Miles, \& E. Miles (Eds.), Dyslexia and Mathematics (pp. 94-119). London: Routledge.

Desforges, C., \& Abouchaar, A. (2003). The Impact of Parental Involvement, Parental Support and Family Education on Pupil Achievement and Adjustment: A Literature Review. London: Department of Education and Skills.

Drath, W. H., McCauley, C. D., Palus, C. J., Van Velsor, E., O’Connor, P. M., \& McGuire, J. B. (2008). Direction, Alignment, Commitment: Toward a More Integrative Ontology of Leadership. The Leadership Quarterly, 19, 635-653. http://dx.doi.org/10.1016/j.leaqua.2008.09.003

Edwards, A. (2009). Relational Agency in Collaborations for the Well-Being of Children and Young People. Journal of Children's Services, 4, 33-43. http://dx.doi.org/10.1108/17466660200900004

Emirbayer, M., \& Mische, A. (1998). What Is Agency? American Journal of Sociology, 103, 962-1023. http://dx.doi.org/10.1086/231294

Goodall, J., \& Vorhaus, J. (2011). Review of Best Practice in Parental Engagement. London: Department of Education.

Guajardo, J. J., \& Woodward, A. L. (2004). Is Agency Skin Deep? Surface Attributes Influence Infants’ Sensitivity to GoalDirected Action. Infancy, 6, 361-384. http://dx.doi.org/10.1207/s15327078in0603_3

Hembree, R. (1990). The Nature, Effects, and Relief of Mathematics Anxiety. Journal for Research in Mathematics Education, 21, 33-46. http://dx.doi.org/10.2307/749455

Jeynes, W. (2012). A Meta-Analysis of the Efficacy of Different Types of Parental Involvement Programs for Urban Students. Urban Education, 47, 706-742. http://dx.doi.org/10.1177/0042085912445643

Jeynes, W. H. (2005). Effects of Parental Involvement and Family Structure on the Academic Achievement of Adolescents. Marriage \& Family Review, 37, 99-116. http://dx.doi.org/10.1300/J002v37n03_06

Johnston-Wilder, S., \& Lee, C. (2008). Does Articulation Matter When Learning Mathematics? Proceedings of the British Society for Research into Learning Mathematics, 28, 54-59.

Johnston-Wilder, S., \& Lee, C. (2010). Developing Mathematical Resilience. BERA Annual Conference 2010, University of Warwick, 1-4 September 2010.

Johnston-Wilder, S., Lee, C., Garton, L., Goodlad, S., \& Brindley, J. (2013). Developing Coaches for Mathematical Resilience. ICERI 2013: 6th International Conference on Education, Research and Innovation, Seville, 18-20 November 2013.

MacDonald, G., \& Valdivieso, R. (2001). Measuring Deficits and Assets: How We Track Youth Development Now, and How We Should Track It. Trends in Youth Development, 6, 155-186. http://dx.doi.org/10.1007/978-1-4615-1459-6_6 
Miller, D. K. (1984). Conditions Affecting the Occurrence of Causal Attributions in Response to a Learned Helplessness Induction. Lubbock: Doctor of Philosophy, Texas Tech University.

Morrison, G. M., \& Allen, M. R. (2007). Promoting Student Resilience in School Contexts. Theory into Practice, 46, 162169. http://dx.doi.org/10.1080/00405840701233172

OECD (2013). Mathematics Self-Beliefs and Participation in Mathematics-Related Activities. PISA 2012 Results: Ready to Learn-Students' Engagement, Drive and Self-Beliefs (Volume III). PISA, OECD Publishing.

http://www.oecd.org/pisa/keyfindings/PISA2012-Vol3-Chap4.pdf

Overmier, J. B. (2002). On learned Helplessness. Integrative Physiological \& Behavioral Science, 37, 4-8. http://dx.doi.org/10.1007/BF02688801

Overmier, J. B., \& Seligman, M. E. P. (1967). Effects of Inescapable Shock upon Subsequent Escape and Avoidance Learning. Journal of Comparative and Physiological Psychology, 1, 23-33.

Patall, E. A., Cooper, H., \& Robinson, J. C. (2008). The Effects of Choice on Intrinsic Motivation and Related Outcomes: A Meta-Analysis of Research Findings. Psychological Bulletin, 134, 270-300.

http://dx.doi.org/10.1037/0033-2909.134.2.270

Rotenberg, V. S. (2012). Religious Education as a Prevention of Learned Helplessness and Depression: Theoretical Consideration. ANS: The Journal for Neurocognitive Research, 54, 1-9.

Russell, R. A. (2002). Parents Helping Their Children with Mathematics. Ph.D. Thesis, Bristol.

Schoon, I. (2006). Risk and Resilience: Adaptations in Changing Times. Cambridge: Cambridge University Press. http://dx.doi.org/10.1017/CBO9780511490132

Seligman, M. E. (1972). Learned Helplessness. Annual Review of Medicine, 23, 407-412. http://dx.doi.org/10.1146/annurev.me.23.020172.002203

Sewell Jr., W. H. (1992). A Theory of Structure: Duality, Agency, and Transformation. American Journal of Sociology, 98, 1-29. http://dx.doi.org/10.1086/229967

Singer, M. (2012). Human Behavior in the Prison Environment: Adaptation as Survival. Journal of Diverse Social Work, 3, 53.

Stake, R. E. (1967). The Countenance of Educational Evaluation. Teachers College Record, 68, 523-540.

Thomas, G. (2011). A Typology for the Case Study in Social Science Following a Review of Definition, Discourse, and Structure. Qualitative Inquiry, 17, 511-521. http://dx.doi.org/10.1177/1077800411409884

Vincent, C. (2001). Social Class and Parental Agency. Journal of Education Policy, 16, 347-364. http://dx.doi.org/10.1080/0268093011-54344

Waxman, H. C., Gray, J. P., \& Padron, Y. N. (2003). Review of Research on Educational Resilience. Berkeley, CA: UC Center for Research on Education, Diversity and Excellence. https://escholarship.org/uc/item/7x695885

Wiggins, J. S. (1991). Agency and Communion as Conceptual Coordinates for the Understanding and Measurement of Interpersonal Behavior. In D. Cicchetti, \& W. M. Grove (Eds.), Thinking Clearly about Psychology: Essays in Honor of Paul E. Meehl (pp. 89-113). Minneapolis, MN: University of Minnesota Press.

Wyness, M. G. (2010). Children and Young People’s Participation within Educational and Civic Settings: A Comparative Case Study Approach to Research. In D. Hartas (Ed.), Educational Research and Inquiry: Qualitative and Quantitative Approaches. London: Continuum International Publishing Group.

Zaretskii, V. (2009). The Zone of Proximal Development: What Vygotsky Did Not Have Time to Write. Journal of Russian and East European Psychology, 47, 70-93. http://dx.doi.org/10.2753/RPO1061-0405470604 